\title{
Обзор технологий разработки малых и средних глубоководных месторождений нефти и газа
}

\author{
И.В. Вельмескин ${ }^{a}$, О.Е. Кочнева ${ }^{b}$ \\ арермский государственный национальный исследовательский универси- \\ тет, 614990, Пермь, ул. Букирева, 15. E-mail: Ivanvelmeskin@gmail.com \\ bермский национальный исследовательский политехнический универси- \\ тет, 614990, Пермь, Комсомольский пр., 29 \\ E-mail: olgakochneva777@yandex.ru \\ (Статья поступила в редакиию 30 марта 2015 г.)
}

\begin{abstract}
На современном этапе развития глубоководной добычи нефтяные компании столкнулись с проблемой нерентабельности малых и средних месторождений. Технологии, применяемые для добычи, сбора и хранения углеводородов в глубоководье, являются крайне сложными и дорогостоящими, что не позволяет добиться даже минимальной рентабельности проектов с объемом добычи до 50 тыс. баррелей нефти. Проанализированы применяемые на сегодня технологии добычи и возможные альтернативы по снижению конечной стоимости проекта и вывода малых месторождений на минимальную рентабельность.

Ключевые слова: плавучая система добычи, хранения и транспортировки нефтепродуктов, добываюшая платформа, водоотделяющая колонна, швартовочная система.
\end{abstract}

DOI: 10.17072/psu.geol.27.93

В связи с высокой стоимостью разработки глубоководных месторождений инвестиции нефтяных компаний направлены на разработку крупных залежей. Небольшие по запасам месторождения находятся вне зоны рентабельности, поэтому их разработка не представляет интереса [3].

Проекты разработки небольших нефтяных залежей более чувствительны к изменениям капитальных затрат, нежели к эквивалентным изменениям значений операционных. Как же можно снизить капитальные затраты и вывести разработку небольших по объёму запасов глубоководных месторождений на минимально допустимый уровень рентабельности? На этот вопрос мы постараемся дать ответ.

Подводная технология добычи нефти и природного газа за 50 лет прошла успешный путь от новшества до апробированных технико-технологических peшений, которые с каждым годом все чаще применяются при разработке морских месторождений и сейчас являются практически безальтернативными при освоении глубоководных нефтегазовых месторождений [4].

На сегодняшний день для разработки глубоководных месторождений применяются несколько типов добывающих платформ: плавучая система добычи, хранения и выгрузки нефтепродуктов (FPSO - Floating Production Storage Offloading, рис.1), платформа поплавкового типа (SPAR - Single Point Mooring And Reservoir), платформа на натяжении (TLP - Tension Leg Platform), полупогружная платформа (Semi-Submersible). 


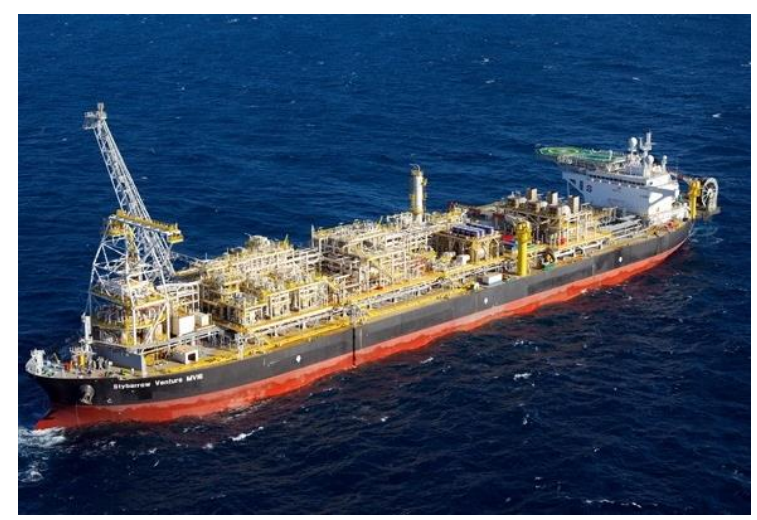

Рис 1. Плавучая система добычи, хранения и выгрузки нефтепродуктов

В условиях глубоководной добычи при значительной удалённости от континентальной инфраструктуры (до 100 км от береговой линии) необходимо учитывать мощности для хранения нефтепродуктов, поэтому не будем описывать каждый тип платформ, а сосредоточимся на одном, наиболее релевантном для нас варианте, имеющем главное преимущество по отношению к остальным, - возможность хранить углеводороды на борту (платформа типа FPSO) [2].

Первое в мире судно типа FPSO было представлено в 1977 г. в испанской части Средиземного моря на месторождении Castellon компании Шелл (глубина составляла 117 м). Последовав этому примеру, бразильский оператор Петробрас переоборудовал танкер «Presidente Prudente de Moraes» и поставил на разработку месторождения Garoupa в 1978 г.[5].

FPSO - это плавучая система добычи, хранения и выгрузки нефтепродуктов. Она является одной из ряда различных типов плавучих систем, используемых сегодня в нефтяной и газовой промышленности. Внешне она напоминает судно, но спроектирована абсолютно иначе и перевозит не только всю необходимую продукцию и технологическое оборудование, обычно относящееся к платформе нелетучих масел и газопромысловой платформе, но и резервуары для сырой нефти, добываемой из скважин на морском дне. Она надолго пришвартовывает- ся в отведенном ей месте и соединяется со скважинами гибкой водоотделяющей колонной.

В отличие от остальных типов платформ (SPAR, TLP, Semi-Sub), платформа типа FPSO имеет трюм-секции для хранения нефтепродуктов, так как чаще всего за основу для переоборудования используются бывшие нефтетанкеры [6]. Наличие собственного трюма позволит сократить капитальные затраты на строительство плавучих резервуаров, прокладку трубопроводов и коммуникаций к ним, сэкономить на обслуживании, персонале и как следствие - снизить конечную величину капитальных и операционных затрат.

Наряду с преимуществами есть и существенные недостатки этой конструкции. К основным из них следует отнести «карабельную» основу формы, в связи с чем она не устойчива к морской качке, а следовательно, непрерывность технологического процесса зависит от климатических условий (при сильной качке возможна временная остановка), невозможность размещения фонтанных арматур скважин на поверхности платформы. «Привязывается» FPSO только к подводно-добычным комплексам (манифольдам), подводящим поток жидкости по гибким райзерам к борту платформы либо к турельной системе (рис.2). Турельная швартовочная система представляет собой сложный комплекс подшипников трения, который позволяет вращаться судну вокруг оси турели. Через неё проходит поток жидкости от скважин к системе подготовки на платформе, осуществляется подвод химических реагентов для ингибирования скважин, борьба с гидратообразованием, закачка воды для поддержания пластового давления и т.д. Турель бывает двух основных типов внешняя (крепится к носовой части судна) и внутренняя (монтируется внутри корпуса). 


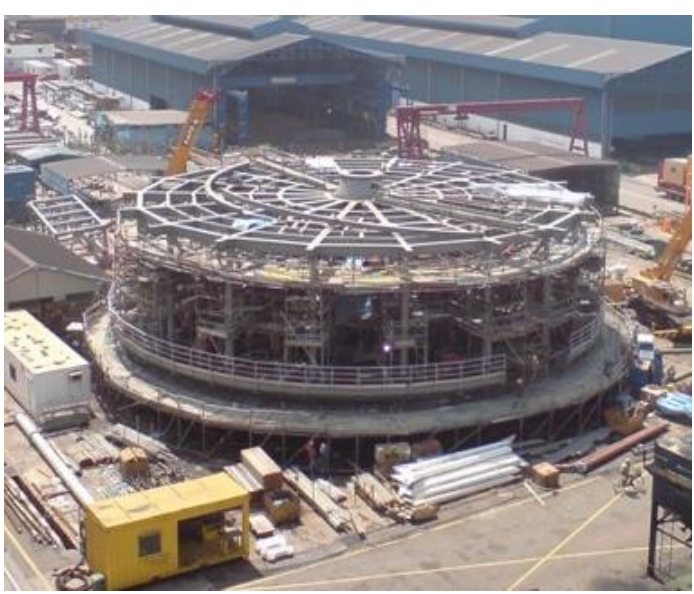

Рис. 2. Турельная система сбора на FPSO

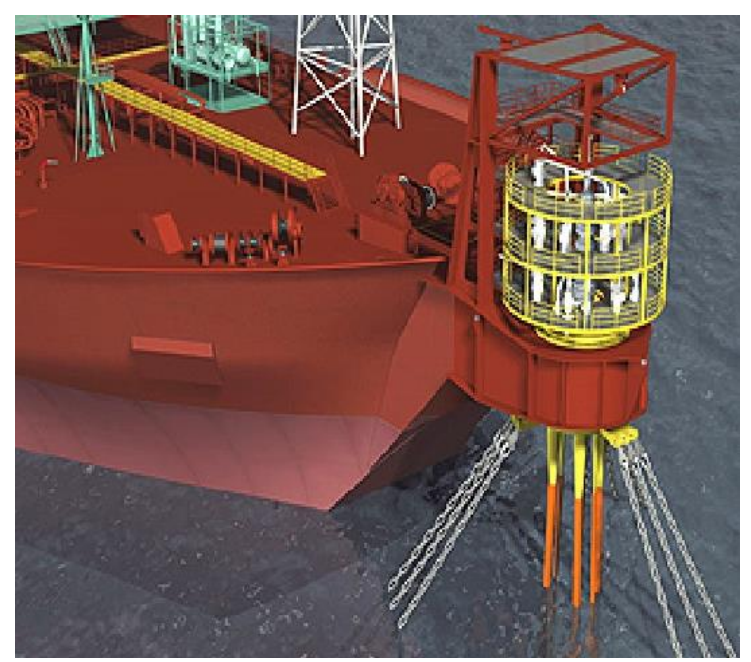

Рис 3. Строительство турели на верфи в Сингапуре

Строительство турели часто производится отдельно от платформы, так как занимает огромные мощности (рис.3), затем монтируется на месте предполагаемой дислокации FPSO (в случае с внешней турелью). Стоимость такой системы сбора может доходить до $30 \%$ от стоимости самой платформы.

Одним из ключевых факторов осложнения разработки средних и малых нефтяных месторождений в глубоководье является стоимость платформы. При добыче от 30 до 50 тысяч баррелей в сутки нецелесообразно применение дорогостоящих систем сбора турельного типа, строительство плавучих хранилищ.

Для выхода на минимальную окупаемость таких проектов нефтяным компаниям необходимо искать альтернативные более экономичные технико-технологические решения [7].

Sevan Marine - норвежская компания, которая конструирует, владеет и управляет плавучими морскими установками. Отличительным и уникальным продуктом компании является платформа SSP (стабилизированная платформа Sevan цилиндрического типа), используемая для добычи и бурения в различных климатических условиях. Компания основана в Арендале, имеет офисы в Танангере, Тронхейме, Аскере, Рио-де-Жанейро, Аракажу и Сингапуре. Акции компании торгуются на фондовой бирже Осло.

Платформа SSP (рис.4) - это конструкция цилиндрической формы, подчиняющаяся тем же принципам устойчивости, что и классические корабли. SSP-300 относится к SSP платформам, имеющим возможность вмещать до 300 тыс. баррелей нефтепродуктов. В отличие от платформ поплавкового типа (SPAR), SSP шиpe по отношению к её высоте, обычно это меньше одной трети ее диаметра. При добыче 30 тыс. баррелей в сутки возможно хранение углеводородов до 10 дней, что вполне достаточно для периода отгрузки на танкер, который занимает в среднем 4-6 дней.

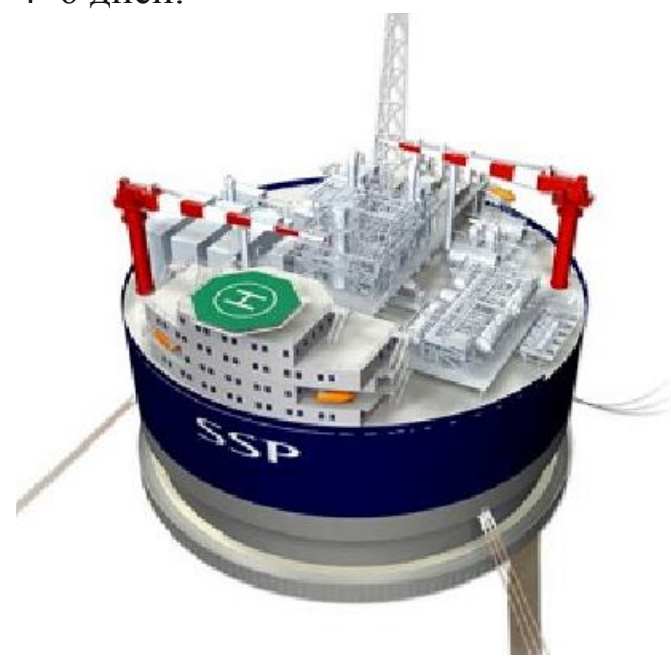

Рис. 4. Стабилизированная платформа Sevan (ССПЗ00)

Кругообразная форма компенсирует любое воздействие течений, поскольку, в зависимости от их направления морская 
водная поверхность испытывает те же гидравлические сопротивления, что и корабли. Следовательно, платформа SSP достаточно устойчива, не нуждается в турельных системах сбора и как следствие отсутствие риска остановки технологического процесса в результате сильного шторма [8]. Для управления входящим потоком нефти есть возможность приема райзеров через центральный мунпул (сквозное отверстие в центральной части платформы, рис.5), при сохранении многоточечной системы швартовки, отдельно развернутой вокруг платформы, а не от турели.

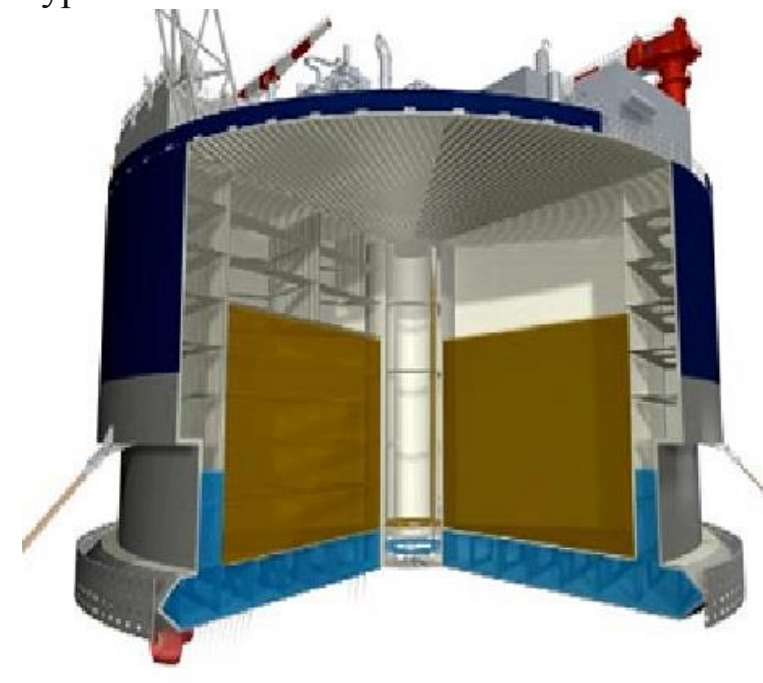

Рис. 5. Емкости для хранения УВ и центральный тоннель

SSP-300 не только «предлагает» все плюсы обычных судов, такие как большая емкость хранения, загрузка палубы и ее просторность, но и имеет динамику движения, схожую или даже лучшую, чем у полупогружных платформ (SemiSubmersible). Строительство облегчается внутренней симметрией, которая так же дает доступ ко всем резервуарам, таким образом, уменьшая число труб, кабелей и внутренних коммуникаций.

Подсчитано, что на платформе SSP требуется только $30 \%$ от общей длины труб и кабелей, необходимых для эквивалентного FPSO. Это, в свою очередь, серьезное уменьшение сложности инженерного проекта и увеличение долговеч- ности и надежности конструкции. Кроме того, в сравнении с FPSO SSP-300 не нуждается в паре турель-шарнирного оборудования, которое не только дорогое, но и требует высокого уровня обслуживания, а также используется без захода на капитальный ремонт в док верфи до 15-20 лет. SPP-300 принимает большое число райзеров через ее балластные танки, направляя их от палубы до входных манифольдов. Это расположение сделано не только с целью улучшить безопасность и облегчить операции, но и защитить райзеры и шланго-кабели от столкновения судов. SSP-300 имеет диаметр 63 м и высоту 30 м и максимальную осадку 20 м. Она существенно отличается от платформы поплавкового типа (SPAR), с которой ее часто сравнивают: нет дорогостоящей транспортировки и установки в связи с большой осадкой, в отличие от SPAR SSP шире ее вертикальной высоты. Возможная нагрузка на палубе SSP-300 свыше 9000 т, что более чем достаточно для размещения всего технологического оборудования [10].

Двухслойный корпус ССП играет важную конструктивную роль - обеспечивает горизонтальную жёсткость за счёт модулей в сочетании с центральным силовым стержнем, с которым они соединены вертикальными балками и горизонтальными жесткими поперечинами (рис.6).

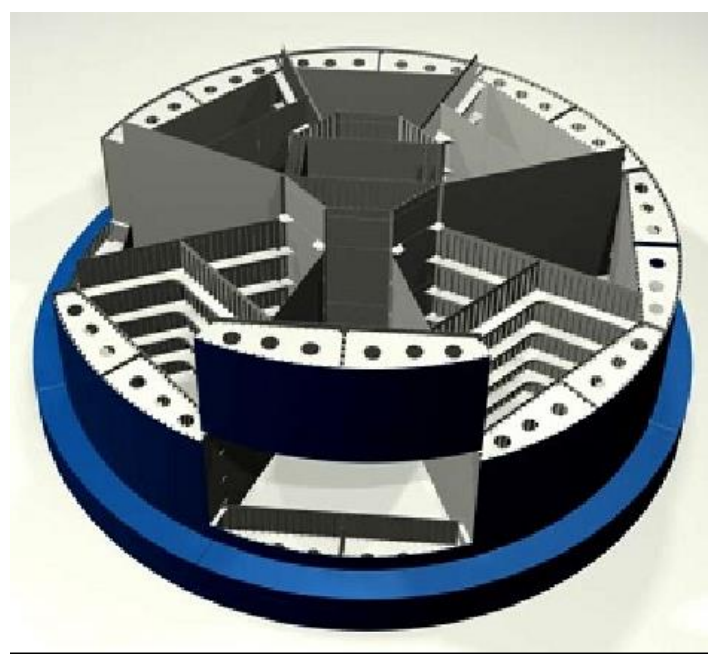

Рис. 6. Внутреннее строение платформы ССП 
Переборки резервуаров необходимы только для армирования каждого танка, когда каждые два резервуара делятся одной общей перегородкой. Это также является преимуществом симметрии конструкции, которая снижает вес стали, но при этом добавляется устойчивость.

Двойное дно и верхняя палуба работают как радиальные перекладины, придающие корпусу увеличенные вертикальную и горизонтальную жесткость. В конечном результате - вновь уменьшение массы необходимой стали и строительных затрат. Круглая форма так же предусматривает гораздо меньшие изгибающие моменты, воспринимаемые структурой, которая уменьшает провисание и коробление металла.

Одна из сильных особенностей SSP концепции в том, что высокая степень симметрии способствует блочной модульности. Что как видно на рис. 6, весь корпус сделан всего из 8 разных типов строительных модулей. При такой конструкции строительство будет выигрывать за счет «кривой обучения» (learning curve), где эффективность в строительстве блоков возрастает в процессе работы.

Отметим еще одно преимущество симметрии: трафаретный дизайн включает всего 3 различных размера стальных листов и 3 различных толщины стали, добавляя новый уровень модульности и простоты в конечный детальный инженерный дизайн.

Для сравнения, для строительства эквивалентного корпуса судна необходимо обычно около 400 различных размеров стальных пластин различной толщины, включая процесс оптимизации распределения веса стали, что занимает значительно больше времени и труда. Такой высокий уровень модульности указывает на применение систем автоматизации во время производства блоков. Если правильно использовать эти методы, то автоматизация приведет к новому уровню контроля за качеством и эффективностью, о которых сегодня можно только догадываться. Постройку SSP-300 можно осуще- ствить практически в любой верфи. Корпус может быть возведен в сухом доке или на земле и затем спущен на воду [11].

Гидродинамическое поведение SSP было протестировано на океанической базе Маринтек в Трондхейме, Норвегия, где была заверена отличная динамика SSP для угловых и вертикальных движений. Тест симулировал морские условия в Северном море и акватории Бразилии, соответствующие экстремальным погодным условиям и многонаправленности течений. Оба сценария исследовались на условия шторма. Воздействия килевой качки и вращений поперёк корпуса SSP-300 были очень малы, в действительности, этот показатель лучше, чем у большинства полупогружных платформ. Относительно воздействия горизонтальных смещений SSP-300 превышает показатели по устойчивости полупогружных платформ в широких спектрах волнения моря. Этот показатель очень значителен для усталостных нагрузок стальных гофрированных райзеров, которые крайне чувствительны к высокочастотным колебаниям. Тестируемая модель продемонстрировала, что с подходящим дизайном трюмного короба подвижность SSP-300 оптимальна, чтобы не допустить возникновения усталостных напряжений на райзерах.

На сегодняшний день на воду спущено три платформы типа SSP.

1. Piranema Spirit в акватории Бразилии, где глубина воды достигает 1100 м. Владелец платформы нефтяная компания Петробрас, месторождение Piranema c уровнем добычи - 30 тыс. бар/сут. было запущено в 2007 г., план разработки рассчитан на 11 лет с возможной пролонгацией на 5 лет.

2. Hummingbird Spirit в Северном море, глубина 120 м. Месторождение Chestnut в акватории Великобритании вышло на плановую добычу 30 тыс. бар/сут в 2009 г. Компания Центтрика Энерджи Апстрим рассчитывала вести добычу всего 2,5 г., однако в 2013 г. контракт был продлён до 2016 г. 
3. Voyageur Spirit - месторождение Huntington field в Северном море, акватории Великобритании, глубина воды в этой зоне - 120 м. Уровень добычи 30 тыс. бар/сут был достигнут в 2009 г. Компания E.ON Ruhrgas UK E\&P планирует вести добычу 5 лет с возможной пролонгацией.

Безаварийный опыт эксплуатации платформы SSP доказал на практике применимость данной технологии в широком спектре климатических условий и операций. Относительно низкая стоимость и простота конструкции позволили нефтяным компаниям вести добычу в ранее признанных нерентабельными месторождениях [12].

Добывающая отрасль сталкивается с постоянно растущими расходами на глубоководную разработку. Месторождения с небольшими запасами остаются малорентабельными, но в настоящее время, когда не осталось «легкой» нефти, добывающие компании приступили к их разработке, о чем нельзя было даже догадываться десять лет назад. На сегодняшний день есть альтернативные технологии классическим, апробированным десятилетиями технологиям, способные вывести месторождения с добычей до 50 тыс. баррелей в сутки в ряд рентабельных и тем самым открыть новые возможности для инвестиций.

Благодаря относительно простой конструкции ССП-300 компании Sevan Marine может быть построена практически на любой верфи, так как не выходит за рамки ограничений по габаритам. Для строительства платформ типа FPSO, TLP и SPAR доступно ограниченное число верфей из-за размеров и сложности их конструкции. SSP-300 основана на проверенных принципах проектирования и состоит из обычных стальных конструкций [13]. Простота и высокая модульность сокращают время на проектирование и строительство. Отсутствие необходимости в дорогостоящих турельных системах швартования снижает риск негативного воздействия на гибкие трубы.
Компания Sevan Marine спроектировала дизайн-проект добывающих платформ будущего, способных дать толчок развитию новым проектам разработки малых глубоководных месторождений по всему миру. Безусловно, геологические риски очень велики, однако уже сейчас небольшие нефтедобывающие компании выходят на этот рынок и ведут успешную добычу углеводородов в самых сложных климатических условиях.

\section{Библиографический список}

1. Адамяни П.П., Гусейнов Ч.С., Иванеи В.К. Проектирование обустройства морских нефтегазовых месторождений. М.: ООО «ЦентрЛитНефтеГаз», 2005. 345 с.

2. Бородавкин П.П. Морские нефтегазовые сооружения: учебник для вузов. Ч. 1. Конструирование. М.: ООО «НедраБизнесцентр», 2006. 237 с.

3. Бородавкин П.П. Морские нефтегазовые сооружения: учебник для вузов. Ч. 2. Технология строительства. М.: ООО «НедраБизнесцентр», 2007. $278 \mathrm{c.}$

4. Грудниикий Г.В., Грудницкий С.В., Егоров С.И., Мамутов Р. Морские нефтегазовые точечные причалы. М., 2011. 368 c.

5. Гусейнов Ч.С. Освоение углеводородных ресурсов Северного Ледовитого океана ближайшая и неотложная перспектива // Бурение и нефть. 2012. №1. С.45-50.

6. Гусейнов Ч.С., Мусабиров А.А. Ледостойкая самоподъёмная платформа для замерзающего мелководья и способ последовательного монтажа сменных палуб // Бурение и нефть. 2012. №10. М.: ООО «Медиа Гранд». С. 18-20.

7. Егоров С. И. Актуальные проблемы проектирования морских нефтегазовых точечных причалов // Нефть, газ и бизнес. 2012. № 7. C. 3-5.

8. Катюха П.Б. Тенденции и перспективы эволюции нефтетрейдинга в России // Нефть, газ и бизнес. 2012. № 7. С. 6-11.

9. Правила классификации, постройки и оборудования плавучих буровых установок (ПБУ) и морских стационарных платформ (МСП). СПб.: Российский морской регистр судоходства, 2012.

10. Шибакин С.И., Шибакин Р.С., Булавин В.Д. Функциональные мобильные уста- 
новки для условий мелководного шельфа замерзающих морей // Состояние и перспективы освоения морских нефтегазовых месторождений: сб. науч. тр. М.: ООО «ВНИИГАЗ», 2003. С. 231-238.

11. Parker G. The FPSO Design and Construction Guidance Manual. Хьюстон, США. Reserve Technology Institute, 1999. $121 \mathrm{p}$.

12. Parshall J. Evolving Subsea Technology
Tackles Huge New Riscks of Today's Projects // Journal of Petroleum Technology. 2008. May P. 40-47.

13. Permanent versus disconnectable FPSOs, LUO Yong and WANG Hong-wei, Deepwater Engineering Research Center, Harbin Engineering University, Harbin 150001, China. P. 6.

\title{
Overview of Technologies for Development of Small and Medium-sized Deep-water Oil and Gas Fields
}

\author{
I.V. Velmeskin ${ }^{a}$, O.E.Kochneva ${ }^{b}$ \\ aPerm State University, 15 Bukireva Str., Perm 614990, Russia. \\ E-mail: Ivanvelmeskin@gmail.com

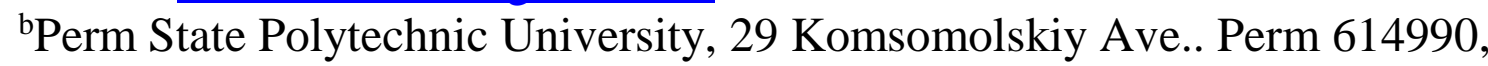 \\ Russia. E-mail: Olgakochneva777@ yandex.ru
}

\begin{abstract}
At present, the oil companies, engaged in the deep water oil production, encountered the problem of unprofitability of development of small and medium-size fields. Technology, which is applied for the extraction, collection and storage of hydrocarbons in deep-water conditions, is very complicated and expensive. It is noted that projects with annual production of up to 50 thousand barrels are not able to provide even a minimal profitability. In this article, we analyzed up-to-date oil production technologies and tried to identify possible alternatives for reducing the final cost of the project, and providing minimum profitability of small deposits.
\end{abstract}

Keywords: floating production systems; storage and transportation of petroleum products; production platform; riser column; tie-down system.

\section{References}

1. Adamyants P.P., Guseinov C.S., Iwaniec V.K. 2005. Proektirovanie obustroystva morskikh neftegazovykh mestorozhdeniy [Design of construction of the offshore oil and gas deposits]. Moskva, JSC "TsentrLitNefteGaz", p. 345. (in Russian)

2. Borodavkin P.P. 2006. Morskie nefetgazovye sooruzheniya; uchebnik dlya vuzov. Chast 1 . Konstruirovanie [Offshore oil and gas structures: a textbook for high schools. Part 1. Construction]. Moskva, Nedra-Biznestsentr, p. 237. (in Russian)

3. Borodavkin P.P. 2007. Morskie nefetgazovye sooruzheniya; uchebnik dlya vuzov. Chast 2. Tekhnologiya stroitelstva [Offshore oil and gas structures: a textbook for high schools.
Part 2. Construction Technology]. Moskva, Nedra-Biznestsentr, p. 278. (in Russian)

4. Grudnitskii G.V., Grudnitskii S.V., Egorov S.I., Mamut R. 2011. Morskie hefetgazovye tochechnye prichaly [Offshore Oil and Gas single-point moorings]. Moscow, p. 368. (in Russian)

5. Guseinov C.S. 2012. Osvoenie uglevodorodnykh resursov Severnogo Ledovitogo okeana - blizhayshaya i neotlozhnaya perspektiva [Development of hydrocarbon resources in the Arctic Ocean: the nearest and high priority perspective]. Burenie i neft. 1:.45-50. (in Russian)

6. Guseinov C.S., Musabirov A.A. 2012. Ledostoykaya samopodyomnaya platforma dlya zamerzayushchego melkovodya i sposob posledovatelnogo montazha smennykh palub [Ice-resistant self-elevating platform for 
freezing shallow water and technique of successive mounting of removable decks]. Burenie i neft. 10: S. 18-20. (in Russian)

7. Egorov S.I. 2012. Aktualnye problemy proektirovaniya morskikh neftegazovykh tochechnykh prichalov [Actual problems of designing of offshore single-point moorings]. In Neft, gaz i biznes. 7: 3-5. (in Russian)

8. Katyukha P.B. 2012. Tendentsii i perspektivy evolutsii neftetreydinga v Rossii [Trends and prospects of evolution of oil trading in Russia]. Neft, gaz i biznes. 7: 6-11. (in Russian)

9. Pravila klassifikatsii, postroyki i oborudovaniya plavuchikh burovykh ustanovok i morskikh statsionarnykh platform [Code of classification, construction and arrangement of the Mobile Offshore Drilling Units (MODU) and fixed offshore platforms (SMEs)]. St. $\mathrm{Pb}$., Russian Maritime Register of Shipping, 2012.
10. Shibakin S.I., Shibakin P.C., Bulavin V.D. 2003. Funktsionalnye mobilnye ustanovki dlya usloviy melkovodnogo shelfa zamerzayushchikh morey [Functional mobile units for conditions of shallow shelf of the freezing seas]. In Sostoyanie i perspektivy osvoeniya morskikh neftegazovykh mestorozhdeniy. Sbornik nauchnykh trudov, LLC VNIIGAZ, pp. 231-238. (in Russian)

11. Parker G. 1999. The FPSO Design and Construction Guidance Manual. Houston, USA Reserve Technology Institute, p. 121.

12. Parshall J. 2008. Evolving Subsea Technology Tackles Huge New Riscks of Today's Projects. Journal of Petroleum Technology. 60 (5): 40-47. doi: 10.2118/0508-0040-JPT

13. Luo Yong, Wang Hong-Wei. Permanent versus disconnectable FPSOs, Deepwater Engineering Research Center, Harbin Engineering University, Harbin 150001, China, p. 6. 